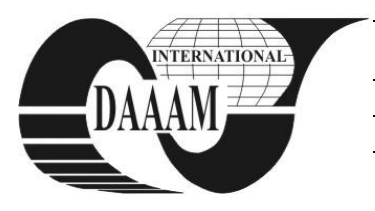

Annals of DAAAM for 2012 \& Proceedings of the 23rd International DAAAM Symposium, Volume 23, No.1, ISSN 2304-1382 ISBN 978-3-901509-91-9, CDROM version, Ed. B. Katalinic, Published by DAAAM International, Vienna, Austria, EU, 2012 Make Harmony between Technology and Nature, and Your Mind will Fly Free as a Bird Annals \& Proceedings of DAAAM International 2012

\title{
APPLICATION OF PLM SYSTEMS IN GROUP TECHNOLOGY APPROACH
}

\author{
SREMCEV, N[emanja]; COSIC, I[lija]; SUZIC, N[ikola] \& STEVANOV, B[ranislav]
}

\begin{abstract}
Group Technology can be considered as a theory of management based on principle that similar things should be done in a similar way. In the context of given research this means product design, production, assembly and production control. This research proposes a model of comparing an old and new production structures to determine whether new product is compatible with the processes and tooling of an existing part families in manufacturing system organized in cells. Model proposes enhancing the cell manufacturing system with performances of Product Lifecycle Management (PLM) software. Hence, the production experience can be quickly obtained, and standard process plans and tooling can be easily developed using PLM system. Possibility of synergetic use of Group Technology (GT) and Product Lifecycle Management (PLM) software is analyzed and discussed.
\end{abstract}

Keywords: Group Technology, PLM systems

\section{INTRODUCTION}

Shortening of product lifecycles and increase of product varieties [1][2] are one of the main characteristics of today's market development. In the race for faster product release and indulging the needs and whishes of customer centric market, design of products has become one of the most important steps in the product development. Furthermore the amount of data and the information that companies are dealing nowadays is increasing on the day to day basis. A great help in solving these problems of today's industry is expected from IT sector and the software tools which are to support the ever growing amount of data.

The development of sophisticated software tools in the field of Product L Management (PDM) and lately the Product Lifecycle Management (PLM) has opened a possibility for efficient product development and successful cooperation between engineers, not only having in mind the concurrent engineering, but also a collaboration between the different functions of the company. Managing of the data with the help of the PDM and PLM software has taken development of products on a whole new level.

In last two decades the applications of PDM and PLM software have become the imperative for concurrent position of the companies in global market.

Applications of PLM software are multiple and are being broadened more and more. The paper will focus on the possibility of application of PLM software in enabling efficient grouping and classification process in group technology (GT) approach. The paper will present a model which will enable the broad abilities of PLM software being used in group technology approach.

\section{PRODUCT LIFECYCLE MANAGEMENT (PLM)}

The necessity to focus attention on the product has driven many companies to increase their efficiency by improving collaboration with partners, customers, and across all other company functions leading to extended enterprise. This has been obtained by the adoption of Product Lifecycle Management (PLM) [3].

Product lifecycle management represents a comprehensive vision for managing all data related to design, production, support and ultimate disposal of manufactured goods, in other words managing and using of enterprise data along the entire product lifecycle [4][5]. PLM software solutions help companies drive productivity with a single source of product and process knowledge, also improving teamwork through instant collaboration.

Three types of data can be stored in PLM data bases: product data, production data and operational support data. Product data describe how the product is designed, manufactured, operated or used, serviced and then retired. Production data focus on all activities associated with the production and the distribution of the product. Operational support data deal with the enterprise's core resources, such as people, finances and other resources required for supporting the enterprise [6]. The required data is distributed to all organizational sectors providing the needed integration.

\section{GROUP TECHNOLOGY APPROACH}

Group technology (GT) is an approach to production system organization which exists for many decades. Group technology first appeared in the book of Mitrofanov [7]. GT is based on the idea of grouping parts by using their similarity. The approach results with cellular organization of machines in production systems [8][9] Fig. 1. This approach gave many benefits to solving problems like long lead times, large setup times, increased Work-In-Progress inventories, large 
inventories of finished goods, poor part quality and high unit costs, as shown in Wemmerlöv and Hyer [10].

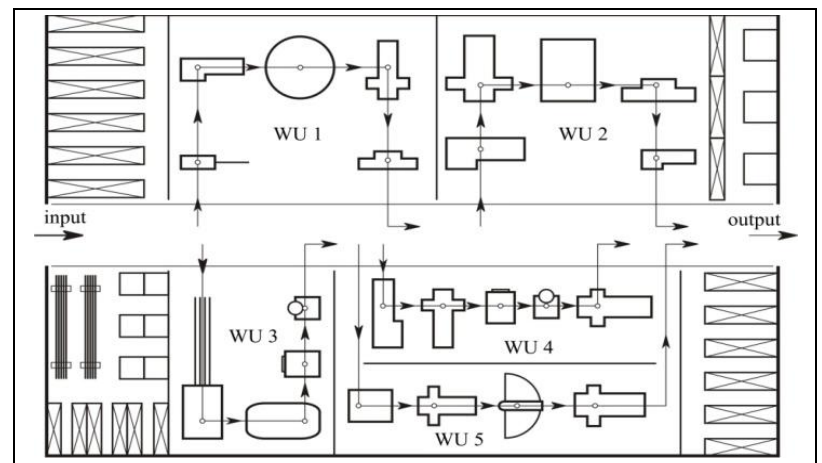

Fig. 1. Cellular layout as the consequence of group technology

Grouping of parts can be achieved in several ways, firstly through finding similarities in part geometry by using classification and coding system (C\&C) Fig. 2. Grouping of parts can also be done by using part drawings which is known as visual inspection method. This method is hardly practical as the part number grows. Another way for part group creation is by finding same processing technology steps that are shared by parts. Parts that have same technological operations can be grouped together. This method is known as Production Flow Analysis (PFA) which is developed by John. L. Burbidge [11] [12]. PFA consists of several phases which include analysis of material flow in production system, forming part families and machine groups, analysis of material flows within cells and analysis of tools concerning the setup time reduction criteria.

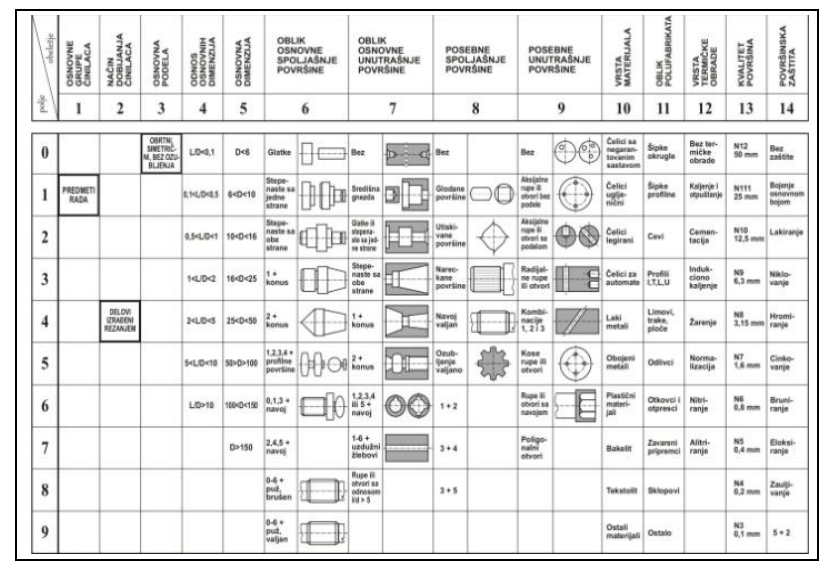

Fig. 2. Example of classification and coding system for rotation parts (part of the classification system KS-IIS-08 - Faculty of Technical Sciences Novi Sad)

In this research the use of classification and coding system in synergy with product lifecycle management software is proposed. The model utilizing advantages of C\&C system and PLM software for successfully bridging the phase between product development and production is given and analyzed.

\section{USING THE PLM TEAMCENTER SOFTWARE IN SERVICE OF GT}

In this paper we show the usage of the PLM Siemens Teamcenter software in services of Group Technology approach on the example of most used three modules of Teamcenter software. One of them is used for the manipulation of files - My Teamcenter, the second one for working with visualization - Digital Mock-Up, and the third one, and most important in this case - Structure Manager for making structures of products and their comparisons.

There are several steps which have to be done in order for product manager to be efficient and effective. Regardless whether the new product is developed because of marketing department recommendations or simple the order is received from the customer, steps are the same. In this research we have assumed that production systems are organized in manufacturing cells and with the use of product part classification. Proposed model (algorithm) is given bellow (Fig. 3.).

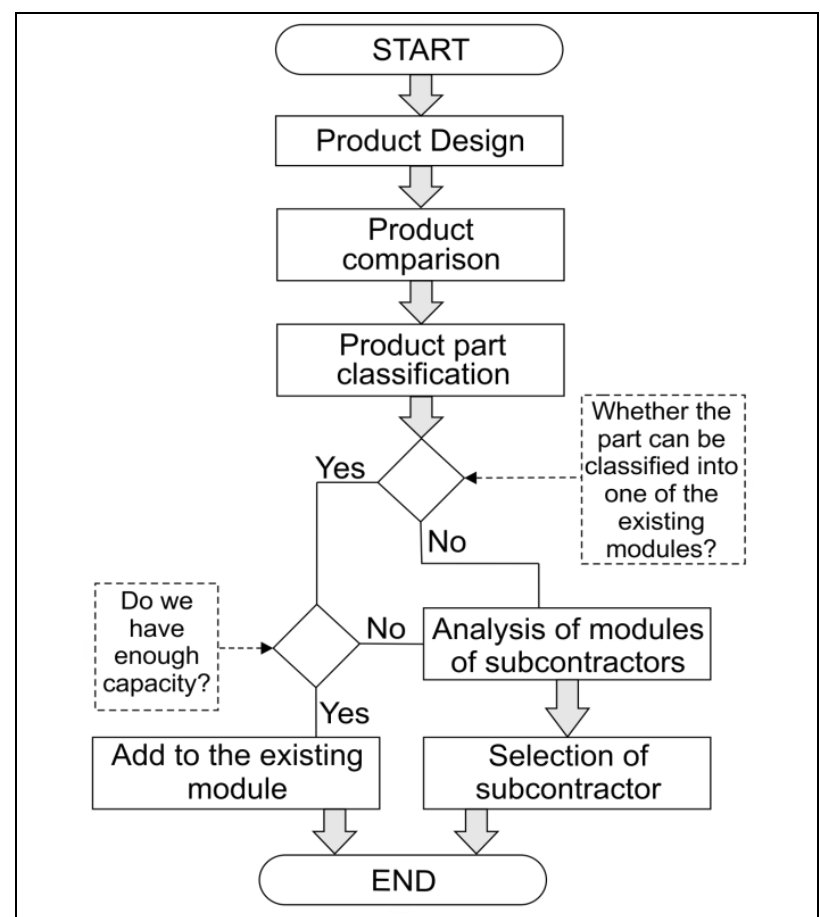

Fig. 3. Steps for product management in cell manufacturing using PLM system

When product manager receives orders, as it is earlier said, regardless if it is from marketing department or customer orders, he starts with making product structures (Fig. 4.). Product manager uses articles from data base and creates product structure according to order. These articles consist of 3D part models, classification number, list of operations which have to be performed on the part and different kind of reports for specific parts.

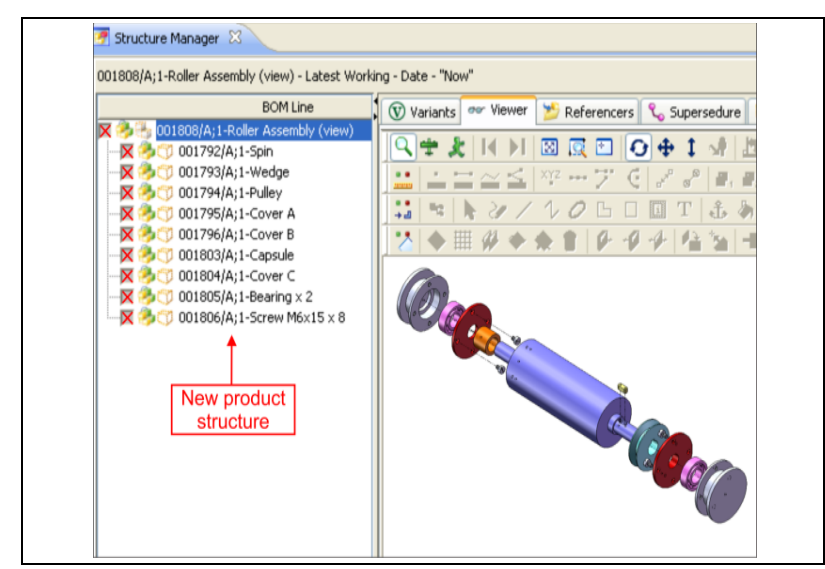

Fig. 4. Newly developed product structure 
If that newly developed product structure requires some specific parts which cannot be found in data base, then product manager sends request to CAD engineers and constructor to design these nonstandard parts.

The design process derives and generates every BOM (Bill of Material) for the product before the commencement of production, manufacturing execution and procurement. The design BOM is divided into BOM groups for production plan, procurement and manufacturing execution [13].

The BOM should also help in the integration of product data and the product structures throughout the product life cycle. Hence, it has been used as a hub of product data for product design, production planning, procurement and financial management. Furthermore the BOM should include not only part list but also product data which defines the product information [14].

In the past, manufacturing industries managed the BOM for MPR (Material Requirement Planning) and production planning in an attempt to transform the design-BOM to a manufacturing-BOM and procurementBOM. Therefore, the M-BOM (Manufacturing-BOM) was managed as one of the most important ways to provide product information. In the 1980's the BOM was required by MPR during the production planning stage to cope with scheduled production for the manufacturers.

Traditionally BOM refers to the manufacturing part list (i.e. not a hierarchical structure). The part list is typically a single-level flat list of necessary components used by manufacturer in product assembly.

After deriving the new product structures, product manager starts with searches of some similar product structures in data base. When similar product is found, comparison is started. Product manager compares two structures to identify changes or differences between the two product structures in order to make further work easier. Now product manager can:

1. Identify component changes between assemblies.

2. Test for consistency between multiple view of the same item.

3. Find differences between differently configured structures.

Product structures can be compared using one of the following standard modes:

1. Single-level mode.

2. Multilevel mode.

3. Lowest level mode.

The given example shows two product structures of mechanical roller. Product manager uses all mentioned mode levels to compare two product structures and find the differences. In the left window we can see product structure parts (components) of the old product, and in the right window is the product structure of new model of roller. The shaded fields are marking the differences between the product structures. The comparison report and report can be seen in the bottom of the figure (Fig. 5).

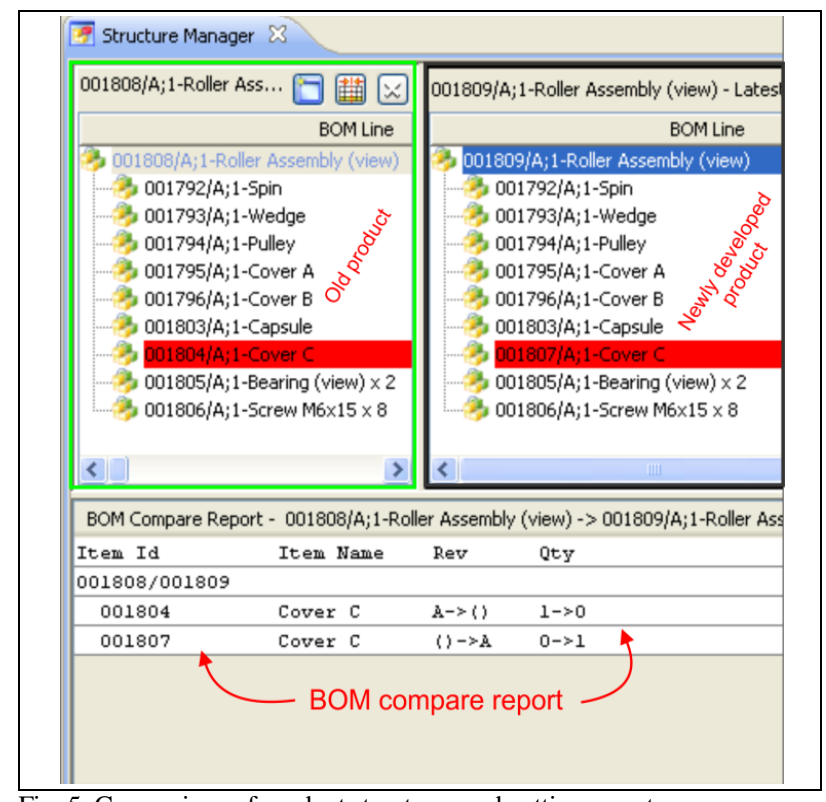

Fig. 5. Comparison of product structures and getting report

These two product structures look similar, even the same, but not for the software and comparison module. On the previous figure there are two shaded fields, and both parts in the two product structures have the same name. Teamcenter software recognizes that these two parts are different and that is because of four holes for screws which old model of roller does not have. If we activate visualization mock-up in Teamcenter, the differences can be seen in 3D model (Fig. 6.).

Now when the differences are known, next important step is to conclude how this will affect the classification number for that part. Furthermore, even if the parts are different, classification number can be the same. The same parts in two product structures are already classified and have their classification numbers but different parts must be checked and their classification number defined.

Once we have all classification numbers for all parts of newly developed production structure, the next step is to check the technological and production capacity for manufacturing or/and assembly of these products. It is important to ask the question: Do we have enough capacity to produce these newly developed products and their parts? If the answer is yes, then the next step is to analyze our modules and workflows. If it is possible the new part will be added to an appropriate existing module or new modules will be created if the parts are new in our production program. After modules are created and if the problems (the part family formations and the machine cell formation) are successful solved, which means that manufacturing cell is dedicated, the production can be launched.

If the existing manufacturing cells cannot produce or do not have enough capacity for production of newly developed parts, then we need to contact our subcontractors to start the production of given parts. Analysis of modules which are produced in subcontractors system is the next step. Estimations of their part family formations and the machine cell formation are necessary for the proper selection of the suitable cellular manufacturing system for production of newly developed products. 


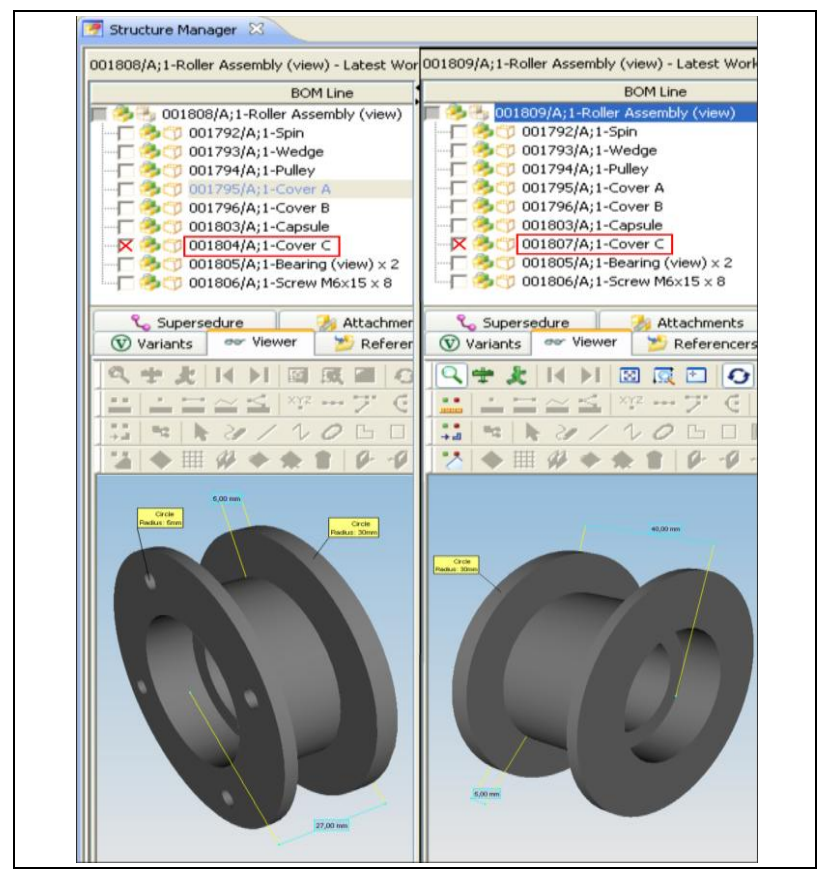

Fig. 6. Checking the differences between two parts

This $R \& D$ phase of product lifecycle management is finished with adding newly developed parts to the appropriate module of our system or with the choice of suitable subcontractor who will make products which we do not have capacity for.

\section{CONCLUSION}

Considering the developed algorithm and example shown in this paper we can conclude that combining of Group Technology and PLM software solution leads to:

1. Faster and easier acceptance of innovations from R\&D engineers.

2. Maintaining of centralized easy accessible product data base.

3. Easy re-use of existing product structures.

4. Shorter time for part classification.

5. Shorter time for product development.

6. Cost saving engineering processes.

7. Less mistakes in product development.

8. Better communication between engineering and management.

9. Easier to find differences between differently configured structures.

10. Transparent product development.

The presented research has its limitations. The main are that the developed model (algorithm) is still a theoretical one and has not been tested in manufacturing practice. Furthermore, although authors found that the usage of classification and coding system (C\&C) in developed model is appropriate, using of other methodologies, like PFA, could also be argued.

The future work will be focused on implementation of proposed model in practice and testing of model's functionality.

\section{ACKNOWLEDGEMENTS}

Research for this article was conducted under the project "Development of software to manage repair and installation of brake systems for rail vehicles", Ministry of Science of Serbia, no. 035050, for the period 2011 ${ }^{\text {th }}$ $2014^{\text {th }}$ year.

\section{REFERENCES}

[1] Zelenović D. (2003) Design of Production Systems, FTN publishing, Novi Sad

[2] Suzić, N., Lazarević, M., Sremčev, N. (2010) Design for Product Variety, 6. Proceedings of Simposium on construction, modeling and designe - KOD, Palić: Faculty of Technical Sciences, pp. 219-222

[3] Vezzetti, E., Moosa, S., Kretli S. A (2011) Product lifecycle management methodology for supporting knowledge reuse in the consumer packaged goods domain, Computer-Aided Design 43 1902-1911

[4] Saaksvuori, A., Immonen, A. (2004) Product lifecycle management. Berlin: Springer-Verlag, Germany

[5] Stark, J. (2005) Product lifecycle management paradigm for 21st century product realisation. London: Springer-Verlag, UK

[6] Maropoulos, P.G., Ceglarek, D. (2010) "Design verification and validation in product lifecycle", CIRP Annals - Manufacturing Technology 59 740-759

[7] Mitrofanov, S.P. (1966). Scientific Principles of Group Technology, English translation, National Library for Science and Technology, Washington, DC (originally published in 1959)

[8] Zelenović, D., Burbidge, L.J., Ćosić., I., Maksimović, R. (1995) The Division of Large Complex Production Systems, Into Independent, Autonomous Units. Proceeding of 13th International Conference of Production Research - ICPR, ,, Global Frontiers in Manufacturing", Jerusalem, Israel, p. 213-215

[9] Zelenović, D., Ćosić, I., Maksimović, R. (1998). Design and reengineering of production systems: Yugoslavian (IISE) approaches, Monograph Group Technology and Cellular Manufacturing - State of-The-Art Synthesis of Research and Practice, Massachusetts, Kluwer Academic Publishers, Vol. 16, p. 517-537, New York, USA

[10] Wemmerlöv, U., Hyer, N.L. (1989). Cellular manufacturing in the U.S. industry: a survey of users, International Journal of Production Research, vol. 27, no. 7, p. 1511-1530

[11] Burbidge, J.L. (1961). The new approach to production, Production Engineer, vol. 40, no. 12, p. 769-793

[12] Burbidge, J.L. (1963). Production flow analysis, Production Engineer, vol. 42, no. 12, p. 742-752

[13] Jang Hyun Lee, Seung Hyun Kim, Kyungho Lee (2012). Integration of evolutional BOMs for design of ship outfitting equipment. Computer-Aided Design 44 (2012), p. 253 - 273

[14] Saaksvuori A., Immonen A. (2004). Product lifecycle management. Springer Verlag 